\title{
Application of Biometric Traits for Predicting Weaning Weight of Dorper Sheep using Path Analysis
}

\author{
Kagisho Madikadike Molabe and Thobela Louis Tyasi*
}

School of Agricultural and Environmental Sciences, Department of Agricultural Economics and Animal Production, University of Limpopo, Private bag X1106, Sovenga 0727, Limpopo, South Africa

*Corresponding author: louis.tyasi@ul.ac.za

\begin{abstract}
Article History: 21-295 Received: 18-Mar-2021 $\quad$ Revised:16-Apr-2021 $\quad$ Accepted: 16-Apr-2021
\section{ABSTRACT}

The current study was conducted to examine the relationship between weaning weight and biometric traits viz; heart girth (HG), rump height $(\mathrm{RH})$, body length $(\mathrm{BL})$, withers height $(\mathrm{WH})$ and sternum height $(\mathrm{SH})$ and, also to determine direct and indirect influence of biometric traits on weaning weight (WW) of Dorper sheep. Dorper sheep lambs (females=23, males=16) were used. Pearson's correlation and path analysis were used for data analysis. Female correlation results indicated that WW had a positive highly significant correlation with $\mathrm{HG}(\mathrm{r}=0.66), \mathrm{BL}(\mathrm{r}=0.66)$ and $\mathrm{RH}(\mathrm{r}=0.55)$, and positively statistical correlation with $\mathrm{WH}(\mathrm{r}=0.45)$ at $\mathrm{P}<0.05$ whereas in males, results demonstrated that WW had a negative highly significant correlation with $\mathrm{HG}(\mathrm{r}=-0.51)$ at $\mathrm{P}<0.05$. Path analysis results on females showed that BL (0.34) had the greatest direct effect on WW while HG $(0.31)$ had the highest indirect contribution on WW, males' results indicated that HG (0.97) had the highest direct contribution on WW while WH (0.69) had the greatest indirect effect on WW. Current study information will assist rural farmer who lack weighing scales to predict weight of their animals for various reasons such as for breeding and marketing purposes and again study outcome will help sheep breeders to select direct and indirect traits influencing weaning weight for improvement.
\end{abstract}

Key words: Biometric traits, Weaning weight, Path analysis, Dorper sheep.

\section{INTRODUCTION}

There is extreme growth in sheep production of about 70.3 million population used for meat and milk production which contributed to the national economy Khan et al. (2018) and lamb production contributes $85-90 \%$ of total income on meat (Kumar et al. 2018). Small ruminant (sheep) plays an important role in reducing poverty in many rural African households, they contribute to the economic living of farmers in terms of providing income when they sell their animals and their products such as milk and meat (König et al. 2017). According to Ayichew (2019), Dorper sheep is a South African native meat breed known for attributes including low maintenance, fast reproduction, muscling, high dressing percentage, high growth rates and can survive under harsh climatic conditions. Wishart et al. (2017) said weaning weight is a major economic parameter used to determine animal growth, judge qualitative traits of an animal and it represents the optimum parameter by which management, health, production, and marketing decisions can be made (Costa et al. 2020). Rather et al.
(2021) indicated that animal morphological structure and improvement ability can be reflected by animal biometric traits, they serve as growth indicators, help in selection during breeding purposes and are also used for estimation of average live weaning weight of animals. Determination of weaning weight using biometric traits may not explain their correlation in all aspects and may provide inadequate information, but a path coefficient and path analysis could be more reliable in determining all the causal effects between the biometric variables (Sabri et al. 2019). Path analysis determines the traits that directly and indirectly affect the weaning weight of an animal; therefore, it provides more detailed information on the correlation between these traits (Tyasi et al. 2017). According to Canul-Solis et al. (2020), there is low availability of resources such as weighing scale in rural areas due to their high cost. Farmers depend on physical estimation of the animal weaning weight (may result in incorrect weight estimate) for purposes such as marketing, medical dosage, feeding and breeding (Hussain et al. 2019). Hence, it is important to practice alternative methods which are easy

Cite This Article as: Molabe KM and Tyasi TL, 2021. Application of biometric traits for predicting weaning weight of Dorper sheep using path analysis. International Journal of Veterinary Science 10(4): 335-339. https://doi.org/10.47278/journal.ijvs/2021.066 
and of low cost such as using biometric traits which will allow rural farmers to determine weight of their animals to monitor the growth of livestock (Chay-Canul et al. 2019). According Mabu et al. (2020) path analysis has been used in previous studies to provide more detailed information on the relationships (direct and indirect) between variables. Other study has been done on Botswana communal sheep and goats using path analysis to predict weaning weight from body measurement traits (Temoso et al. 2017). Path analysis was used to determine the relationship between weaning weight and some linear characteristics in Red Sokoto kids (Shuaibu et al. 2020) and in some exotic sheep breeds (Costa et al. 2020). There is limited literature on analysis technique involving the use of path analysis to determine the relationship between weaning weight and biometric traits of Dorper sheep at weaning. Hence the objectives of the current study were 1) to examine the relationship between weaning weight and biometric traits (heart girth, rump height, body length, withers height, sternum height) of Dorper lamb at weaning, 2) to determine direct and indirect biometric traits affecting weaning weight of Dorper lamb at weaning. The results obtained from the study will be used to predict weaning weight in the field for selection, marketing, feeding, medical dosage purposes at weaning, and the direct and indirect effect will be used for improvement purposes of weaning weight at weaning.

\section{MATERIALS AND METHODS}

\section{Study Area}

The research study was conducted at the University of Limpopo Experimental farm (Syferkuil) in South Africa located next to Mankweng $\left(23^{\circ} 490 \mathrm{~S} ; 29^{\circ} 410 \mathrm{E}\right)$. The area receives a daily average temperature ranging from maximum of $30^{\circ} \mathrm{C}$ to minimum of $13^{\circ} \mathrm{C}$ in summer and $0.6^{\circ} \mathrm{C}$ to $18^{\circ} \mathrm{C}$ in winter with average long-term annual rainfall of $450 \mathrm{~mm}$ per year (Mokoka et al. 2018).

\section{Experimental Animals}

Dorper sheep lambs at weaning (females=23, males=16) were used in the current study. According to Van Wyk and Cloete. (2019), Dorper sheep is a far-tail breed, an adaptable commercial breed with high growth rate associated with large body size, good meat yield, carcass weight and dressing percentage.

\section{Animal Management}

Animals was raised under extensive production system. They were allowed to graze outside during the day and re-called back to their different camps based on their health, age in the afternoons. Animals were vaccinated and dipped frequently for possible diseases and clean water was always provided.

\section{Data Collection}

Biometric traits viz; withers height (WH), heart girth (HG), rump height $(\mathrm{RH})$, body length $(\mathrm{BL})$, and sternum height (ST) were collected randomly from all lambs except sick and pregnant animals by the same person to avoid biasness, arguments and variations. Weaning weight (WW) of each lamb was measured in kilograms using a weighing scale while biometric traits were measured using a tape (cm) following suggestions of Birteeb et al. (2012). Briefly: the distance between the highest point of the shoulder (wither) and the ground surface in relation to level of the fore legs as the withers height, body length as the distance from the anterior shoulder point to the posterior extremity of the pin bone, vertical distance between the lower tip of the sternum and the ground as the sternum height, rump height as the distance between top pelvic girdle and the ground surface in relation to the level of hind legs and body circumference just behind the scapula as the heart girth was be measured.

\section{Statistical Analysis}

Statistical Package for Social Sciences (IBM SPSS Statistics 25) was used for data analysis. Pearson's correlation was used to achieve first objective, and the second objective was achieved through path analysis. Probability of 5\% for significant and probability of $1 \%$ for highly significant between traits was also used. Path analysis was computed following Norris et al. (2015) procedure as described below:

Pyxi $=\frac{\text { biSxi }}{\text { Sy }}$

Where:

Pyxi = path coefficient from Xi to Y ( $\mathrm{i}=\mathrm{HW}, \mathrm{RH}, \mathrm{BL}, \mathrm{SH}$, HG)

bi $=$ partial regression coefficient

$\mathrm{Sxi}=$ standard deviation of $\mathrm{Xi}$

Sy $=$ standard deviation of $\mathrm{Y}$

T-statistic in multiple regression analysis was used to test significance of path coefficient. Path analysis of Indirect effect of biometric traits on weaning weight via direct effect were computed as follows:

IEyxi $=$ rxixjPyxj

Where:

IEyxi $=$ indirect effect of biometric traits through direct effect on weaning weight

rxiyj $=$ correlation coefficient between $\mathrm{i}^{\text {th }}$ and $\mathrm{j}^{\text {th }}$ biometric traits

Pyxj = path coefficient indicating direct effect of jth biometric trait on weaning weight

\section{RESULTS}

\section{Descriptive Statistics}

Descriptive statistics of biometric traits (HG, RH, BL, $\mathrm{WH}, \mathrm{SH}$ ) and weaning weight of females and males of Dorper sheep at weaning are presented in Table 1. Results showed that females had a mean value of $10.31 \mathrm{~kg}$ which is lower than of males $(10.50 \mathrm{~kg})$. Summary of biometric traits in females showed that $\mathrm{HG}$ had the highest mean value of $53.13 \mathrm{~cm}$. followed by BL $(45.83 \mathrm{~cm}), \mathrm{WH}(39.28 \mathrm{~cm}), \mathrm{RH}$ $(38.78 \mathrm{~cm})$ respectively while $\mathrm{SH}$ had the lowest mean value $(33.40 \mathrm{~cm})$ whereas in males, descriptive statistics of biometric traits showed that HG had the highest mean value of $49.50 \mathrm{~cm}$ followed by $\mathrm{BL}(45.17 \mathrm{~cm}), \mathrm{WH}(39.55 \mathrm{~cm})$, WH $(39.55 \mathrm{~cm}), \mathrm{RH}(39.36 \mathrm{~cm})$ respectively, whereas $\mathrm{SH}$ had the lowest mean value of $32.24 \mathrm{~cm}$.

\section{Phenotypic Correlation Among Measured Traits}

Pearson's correlation was used to determine the relationship between weaning weight and biometric traits (HG, RH, BL, WH, SH) and results are presented in Table 2 with females results below diagonal and males' results 
Int J Vet Sci, 2021, 10(4): 335-339.

Table 1: Descriptive statistics of biometric traits of Dorper sheep

\begin{tabular}{lcc}
\hline Traits & Females & Males \\
\hline WW $(\mathrm{kg})$ & $10.31 \pm 5.98 \mathrm{~b}(2.00-25.00)$ & $10.50 \pm 12.54 \mathrm{a}(4.00-55.00)$ \\
HG $(\mathrm{cm})$ & $53.13 \pm 9.06 \mathrm{a}(37.50-70.00)$ & $49.50 \pm 13.19 \mathrm{~b}(16.25-65.00)$ \\
RH $(\mathrm{cm})$ & $38.78 \pm 6.37 \mathrm{~b}(30.00-52.50)$ & $39.36 \pm 8.08 \mathrm{a}(25.00-51.03)$ \\
BL $(\mathrm{cm})$ & $45.83 \pm 8.96 \mathrm{a}(27.50-60.00)$ & $45.17 \pm 7.70 \mathrm{~b}(35.00-63.04)$ \\
WH $(\mathrm{cm})$ & $39.28 \pm 5.22 \mathrm{~b}(30.00-47.50)$ & $39.55 \pm 8.39 \mathrm{a}(25.00-55.00)$ \\
SH $(\mathrm{cm})$ & $33.40 \pm 5.09 \mathrm{a}(25.00-44.30)$ & $32.24 \pm 5.16 \mathrm{~b}(25.00-42.50)$ \\
\hline
\end{tabular}

WW: Weaning Weight, HG: Heart Girth, RH: Rump Height, BL: Body Length, WH: Withers Height, SH: Sternum Height. Values $($ mean \pm SD) bearing different alphabets in a row differ significantly $(\mathrm{P}<0.05)$. Values in parenthesis are range values.

Table 2: Pearson correlation coefficient between weaning weight and biometric traits of Dorper sheep, females below and males above diagonal.

\begin{tabular}{lcccccc}
\hline Traits & WW & HG & RH & BL & WH & SH \\
\hline WW & & $-0.51^{*}$ & $0.21^{\text {ns }}$ & $-0.04^{\text {ns }}$ & $0.00^{\text {ns }}$ & $0.36^{\text {ns }}$ \\
HG & $0.66^{* *}$ & & $0.43^{\text {ns }}$ & $0.62^{* *}$ & $0.71^{* *}$ & $0.52^{* *}$ \\
RH & $0.55^{* *}$ & $0.73^{* *}$ & & $0.62^{* *}$ & $0.54^{* *}$ & $0.53^{* *}$ \\
BL & $0.66^{* *}$ & $0.92^{* *}$ & $0.68^{* *}$ & & $0.57^{* *}$ & $0.66^{* *}$ \\
WH & $0.45^{*}$ & $0.68^{* *}$ & $0.43^{*}$ & $0.66^{* *}$ & & $0.76^{* *}$ \\
SH & $0.27^{\text {ns }}$ & $0.43^{*}$ & $0.35^{\text {ns }}$ & $0.34^{\text {ns }}$ & $0.54^{* *}$ & \\
\hline
\end{tabular}

WW: Weaning Weight, HG: Heart Girth, RH: Rump Height, BL: Body Length, WH: Withers Height, SH: Sternum Height, ns. nonsignificant, *: Correlation is significant at the 0.05 level ( 2 tailed), **: Correlation is significant at the 0.01 level (2-tailed).

above diagonal. Results in females indicated that WW had a positive statistically significant correlation with $\mathrm{HG}$ $(\mathrm{r}=0.66), \mathrm{BL}(\mathrm{r}=0.66), \mathrm{RH}(\mathrm{r}=0.55)$ respectively at $\mathrm{P}<0.01$, $\mathrm{WH}(\mathrm{r}=0.45)$ at $\mathrm{P}<0.05$ and had no significant correlation with $\mathrm{SH}(\mathrm{r}=0.27)$. Relationship amongst biometric traits showed that $\mathrm{HG}$ was statistically and positively significantly correlated to $\mathrm{BL}(\mathrm{r}=0.92), \mathrm{RH}(\mathrm{r}=0.73), \mathrm{WH}$ $(\mathrm{r}=0.68)$ respectively at $\mathrm{P}<0.01$ while statistically correlated to $\mathrm{SH}(\mathrm{r}=0.43)$ at $\mathrm{P}<0.05$. $\mathrm{RH}$ had a positive significant correlation with $\mathrm{BL}(\mathrm{r}=0.68)$ at $\mathrm{P}<0.01$, WH $(\mathrm{r}=0.43)$ at $\mathrm{P}<0.05$ and had non-significant with $\mathrm{SH}$ $(\mathrm{r}=0.35)$. BL had a positive statistical correlation with $\mathrm{WH}$ $(\mathrm{r}=0.66)$ at $\mathrm{P}<0.01$ and $\mathrm{WH}$ was found to be positively correlated to $\mathrm{SH}(\mathrm{r}=0.54)$ at $\mathrm{P}<0.01$.

Correlation results above diagonal (males) demonstrated that WW had a negative statistically significant correlation with only $\mathrm{HG}(\mathrm{r}=-0.51)$ at $\mathrm{P}<0.05$. Relationship between biometric traits showed that $\mathrm{SH}$ was positively and statistically correlated to WH ( $\mathrm{r}=0.76), \mathrm{BL}(\mathrm{r}=0.66), \mathrm{RH}(\mathrm{r}=0.53)$ and $\mathrm{HG}$ $(\mathrm{r}=0.52)$ respectively at $\mathrm{P}<0.01$. WH had a significant correlation with HG ( $\mathrm{r}=0.71)$, BL $(\mathrm{r}=0.57)$, RH $(\mathrm{r}=0.54)$ at $\mathrm{P}<0.01$ and $\mathrm{BL}$ was found to be significantly correlated to $\mathrm{HG}$ $(\mathrm{r}=0.62)$ and $\mathrm{RH}(\mathrm{r}=0.62)$ at $\mathrm{P}<0.01$.

\section{Path analysis}

Direct and indirect effect results of biometric traits on weaning weight of Dorper sheep at weaning for both females and males achieved by path analysis are presented in Table 3 (females) and Table 4 (males). Female results showed that BL (0.34) had the greatest direct effect on WW while HG (0.31) had the highest indirect contribution on WW via BL. Table 4 showing male results indicated that $\mathrm{HG}$ had the highest direct contribution on WW while WH had the greatest indirect effect on WW via HG.

\section{DISCUSSION}

Path analysis has an advantage in providing more detailed information on the relationships (direct and indirect) between these variables (Temoso et al. 2017). The first objective of the current study was to examine the relationship between weaning weight and biometric traits (HG, RH, BL, WH, SH) of Dorper lamb at weaning using
Person's correlation. Correlation results of female demonstrated WW having positive statistically significant correlation with $\mathrm{HG}, \mathrm{BL}, \mathrm{RH}, \mathrm{WH}$ respectively and had no significant correlation with $\mathrm{SH}$. The results indicate that, to improve weaning weight, one must improve $\mathrm{HG}, \mathrm{BL}, \mathrm{RH}$, $\mathrm{WH}$, as they had a positive significant relationship with weaning weight but improving $\mathrm{SH}$ might not have influence on weaning weight. Relationship amongst biometric traits showed that $\mathrm{HG}$ was statistically and positively significantly correlated to $\mathrm{BL}, \mathrm{RH}, \mathrm{WH}, \mathrm{SH}$ respectively. $\mathrm{RH}$ had a positive significant correlation with BL, WH but had no statistically significant relationship with $\mathrm{SH}$. BL had a positive statistical correlation with WH whereas WH was found to be positively correlated to $\mathrm{SH}$. Males correlation results demonstrated that WW had a negative statistically significant correlation with only $\mathrm{HG}$ and had no significant correlation with BL, RH, SH and WH. Therefore, HG was found to be the only traits that has influence on weaning weight however it cannot be used to improve WW and increasing BL, RH, SH and WH might not influence the WW. Relationship between biometric traits demonstrated that $\mathrm{SH}$ had a positive and statistical correlation with $\mathrm{WH}, \mathrm{BL}, \mathrm{RH}$ and $\mathrm{HG}$ respectively. WH had a significant correlation with $\mathrm{HG}, \mathrm{BL}, \mathrm{RH}$ and $\mathrm{BL}$ was found to be significantly correlated to $\mathrm{HG}$ and RH. Other studies have been done on the prediction of weaning weight from body measurements of goats and sheep of communal rangelands in Botswana using path analysis and their descriptive statistics findings are in harmony with the current study results that males had higher average WW than females but same authors disagree with our results where average $\mathrm{HG}$ and $\mathrm{SH}$ of females were higher than of males (Temoso et al. 2017), contrary may be due genetic factor such as type of breeds, furthermore reported similar results that positive statistical correlation was found between WW and HG but disagree with current study results where there was a statistical relationship between WW and SH. Moreover, a high correlation between various body measurements and live weight in sheep was reported and their results are similar with the current study findings on BL, WH and RH (Doğukan et al. 2019). Current correlation results disagree with the results reported by Sabri et al. (2019) on males, disagreement may be due to 
Int J Vet Sci, 2021, 10(4): 335-339.

Table 3: Path analysis coefficient of biometric traits and weaning weight of Dorper (females)

\begin{tabular}{lccccccc}
\hline Traits & $\begin{array}{c}\text { Correlation } \\
\text { coefficient with WW }\end{array}$ & Direct & \multicolumn{3}{c}{ Indirect effect } \\
\cline { 5 - 8 } & $0.66^{* *}$ & 0.25 & HG & RH & BL & WH & SH \\
\hline HG $(\mathrm{cm})$ & $0.55^{* *}$ & 0.14 & 0.18 & 0.10 & 0.31 & -0.00 & 0.00 \\
RH $(\mathrm{cm})$ & $0.66^{* *}$ & 0.34 & 0.23 & 0.09 & 0.23 & -0.00 & 0.00 \\
BL $(\mathrm{cm})$ & $0.45^{*}$ & -0.01 & 0.17 & 0.06 & 0.22 & -0.00 & 0.00 \\
WH (cm) & $0.27^{\text {ns }}$ & 0.01 & 0.12 & 0.05 & 0.12 & -0.00 & 0.00 \\
SH (cm) & &
\end{tabular}

WW: Weaning Weight. HG: Heart Girth. RH: Rump Height. BL: Body Length. WH: Withers Height. SH: Sternum Height.

Table 4: Path analysis coefficient of biometric traits and weaning weight of Dorper (males)

\begin{tabular}{|c|c|c|c|c|c|c|c|}
\hline \multirow[t]{2}{*}{ Biometric traits } & \multirow{2}{*}{$\begin{array}{c}\text { Correlation } \\
\text { coefficient with WW }\end{array}$} & \multirow[t]{2}{*}{ Direct effect } & \multicolumn{5}{|c|}{ Indirect effect } \\
\hline & & & HG & RH & $\mathrm{BL}$ & WH & SH \\
\hline $\mathrm{HG}(\mathrm{cm})$ & $-0.51 *$ & -0.97 & & 0.12 & -0.09 & 0.01 & 0.42 \\
\hline RH (cm) & $0.21^{\mathrm{ns}}$ & 0.28 & -0.41 & & -0.09 & 0.01 & 0.42 \\
\hline $\mathrm{BL}(\mathrm{cm})$ & $-0.04^{\mathrm{ns}}$ & -0.14 & -0.60 & 0.17 & & 0.01 & 0.53 \\
\hline WH (cm) & $0.00^{\mathrm{ns}}$ & 0.01 & -0.69 & 0.15 & -0.08 & & 0.61 \\
\hline $\mathrm{SH}(\mathrm{cm})$ & $0.36^{\mathrm{ns}}$ & 0.80 & -0.50 & 0.15 & -0.09 & 0.01 & \\
\hline
\end{tabular}

WW: Weaning Weight. HG: Heart Girth. RH: Rump Height. BL: Body Length. WH: Withers Height. SH: Sternum Height.

environmental factors such as climatic conditions during data collection. Similar results have been reported by Ambarcioğlu et al. (2017) in Karacabey Merino Sheep where there was a highly positive statistical relationship among live $\mathrm{WW}, \mathrm{BL}$, and $\mathrm{WH}$ and agrees with the present study path analysis results that BL had a direct effect on live WW. We also determined the direct and indirect biometric traits affecting weaning weight of Dorper sheep using path analysis technique. Direct and indirect effect of biometric traits on weaning weight of Dorper sheep results in females showed that BL had the greatest direct effect on WW while HG had the highest indirect effect on WW. Path analysis results in males indicated that $\mathrm{HG}$ had the highest direct effect on WW while WH had the greatest indirect effect on WW. Results implies that BL had the most contribution on WW of females while HG made the most contribution on males. Findings indicates that WW might be improved by direct selection of BL and indirect selection of $\mathrm{HG}$ in females while direct selection of $\mathrm{HG}$ and indirect selection of WH might improve WW in males. It can be concluded that, WW could be estimated using BL and HG in females and $\mathrm{HG}$ and $\mathrm{WH}$ could be used to estimate weaning weight in males. Therefore, BL and $\mathrm{HG}$ are valuable traits in improving WW in females while $\mathrm{HG}$ and $\mathrm{WH}$ are valuable traits in improving $\mathrm{WW}$ in males.

Our association findings on path analysis do not coherent with the results reported by Önder and Abac1. (2015) on path analysis for body measurements on weaning weight of Saanen kids, contrary may be due to use of different breed. Additionally, previous studies put forward path analysis as a useful technique in determining WW using biometric traits in animal breeding in goats (Rotımı et al. 2020), in cattle (Tyasi et al. 2020), in chickens (Egena et al. 2014; Tyasi et al. 2018), in pigs (Al Ard Khanji et al. 2018) and ducks (Yakubu et al. 2015).

\section{Conclusion}

The current study predicted the relationship between weaning weight and biometric traits of Dorper sheep at weaning using Pearson correlation and performed path analysis to determine the direct and indirect effect of biometric traits on weaning weight. Our findings stated that improvement of $\mathrm{HG}, \mathrm{BL}, \mathrm{RH}$ and $\mathrm{WH}$ might lead to increase in weaning weight of female Dorper sheep, whereas path analysis indicated BL and $\mathrm{HG}$ in females, $\mathrm{HG}$ and $\mathrm{WH}$ in males as valuable traits in improving WW. Information from current study will assist rural farmer who lack weighing scales to predict weight of their animals for various reasons such as for breeding, feeding, and marketing purposes and again study outcome will help sheep breeders to select direct and indirect traits influencing weaning weight for improvement.

\section{Acknowledgements}

Authors wish to express their gratitude to the Farmworkers at the University of Limpopo Experimental for their support during data collection and Department of Agricultural Economics and Animal Production, the University of Limpopo for financial support.

\section{Author Contributions}

TLT and KMM designed the experiment, analysed the data the manuscript. KMM performed fieldwork and wrote the manuscript. TLT revised, read, edited, and approved the final manuscript.

\section{REFERENCES}

Al Ard Khanji MS, Llorente C, Falceto MV, Bonastre C, Mitjana $\mathrm{O}$ and Tejedor MT, 2018. Using body measurements to estimate body weight in gilts. Canadian Journal of Animal Science 98: 362-367.

Ambarcioğlu P, Kaya U, Özen D and Gürcan İS, 2017. An Examination of the Relationships Between Live Weight and Body Measurements in Karacabey Merino Sheep Through the Path Analysis Approach. Kafkas Universitesi Veteriner Fakultesi Dergisi 23: 857-863. http://dx.doi.org/10.9775/ kvfd. 2017.17659

Ayichew D, 2019. Dorper sheep cross breeding with indigenous sheep breed in Ethiopia. Journal of Applied and Advanced Research 4: 10-21839. http://dx.doi.org/10.21839/jaar. 2019.v4i1.250

Birteeb PT, Peters SO, Yakubu A, Adeleke MA and Ozoje MO, 2012. Multivariate characterisation of the phenotypic traits of Djallonke and Sahel sheep in Northern Ghana. Tropical Animal Health and Production 45: 267-274. https://doi.org/ 10.1007/s11250-012-0211-4

Canul-Solis J, Angeles-Hernandez JC, García-Herrera RA, del Razo-Rodríguez OE, Rangel HAL, Piñeiro-Vazquez AT, Casanova-Lugo F, Nieto CAR and Chay-Canul AJ, 2020. Estimation of body weight in hair ewes using an indirect 
measurement method. Tropical Animal Health and Production 52: 2341-2347. https://doi.org/10.1007/s11250020-02232-7

Chay-Canul AJ, García-Herrera RA, Salazar-Cuytún R, OjedaRobertos NF, Cruz-Hernández A, Fonseca MA and Canul-Solís JR, 2019. Development and evaluation of equations to predict body weight of Pelibuey ewes using heart girth. Revista Mexicana de Ciencias Pecuarias 10: 767777. https://doi.org/10.22319/rmcp.v10i3.4911

Costa RG, Lima AGVDO, Ribeiro NL, Medeiros AND, Medeiro GRD, Gonzaga Neto S and Oliveira RL, 2020. Predicting the carcass characteristics of Morada Nova lambs using biometric measurements. Revista Brasileira de Zootecnia 49. https://doi.org/10.37496/rbz4920190179

Doğukan ÖZEN, Kocakaya A and Özbeyaz C, 2019. A recursive path model for estimation of the live weight using some body measurements in Awassi sheep. Ankara Üniversitesi Veteriner Fakültesi Dergisi 66: 303-310. http://dx.doi.org/ 10.33988/ auvfd.512959

Egena SSA, Ijaiya AT and Kolawole R, 2014. An assessment of the relationship between body weight and body measurements of indigenous Nigeria chickens (Gallus gallus domesticus) using path coefficient analysis. Livestock Research for Rural Development 26: 29-33. http://dx.doi. org/10.17582/journal.aavs/2021/9.2.189.193.

Hussain MS, Appannavar MM, Yathish HM, Suranagi MD, Biradar US and Asharani AD, 2019. Estimation of body weight and dressed weight in different sheep breeds of Karnataka. International Journal of Veterinary Sciences and Animal Husbandry 4: 10-14.

Khan A, Saleemi MK, Ali F, Abubakar M, Hussain R, Abbas RZ and Khan IA, 2018. Pathophysiology of peste des petits ruminants in sheep (Dorper and Kajli) and goats (Boer and Beetal). Microbial Pathogenesis 117: 139-147. https://doi.org/10.1016/j.micpath.2018.02.009

König EZ, Ojango JM, Audho J, Mirkena T, Strandberg E, Okeyo A.M and Philipsson J, 2017. Live weight, conformation, carcass traits and economic values of ram lambs of Red Maasai and Dorper sheep and their crosses. Tropical Animal Health and Production 49: 121-129. http://dx.doi.org/ 10.1007/s11250-016-1168-5.

Kumar S, Dahiya SP, Malik ZS, Patil CS, 2018. Prediction of body weight from linear body measurements in sheep. Indian Journal of Animal Research 52: 1263-1266.

Mabu MI, Mabu JM, Anka BA and Saheed Y, 2020. Relationship of Testicular Biometrics with Body Weight in Rams: A Slaughter-House Study in Yobe State, Africa. Asian Journal of Biotechnology and Genetic Engineering 3: 39-46.

Mokoka MV, Jordaan JJ and Potgieter MJ, 2018. Correlations between growth parameters and establishment of Vachellia tortilis (Forssk.) Hayne populations in the Limpopo Province, South Africa. http://dx.doi.org/10.1111/aje.12515

Norris D, Brown D, Moela AK, Selolo TC, Mabelebele M, Ngambi JW and Tyasi TL, 2015. Path coefficient and path analysis of body weight and biometric traits in indigenous goats. Indian Journal of Animal Research 49: 573-578. http://dx.doi.org/10.18805/ijar.5564
Önder H and Abacı SH, 2015. Path analysis for body measurements on body weight of Saanen kids. Kafkas Univ Vet Fak Derg 21: 351-354. DOI: 10.9775/kvfd.2014.12500.

Rather MA, Bashir I, Hamdani A, Khan NN, Ahangar SA and Nazki M, 2021. Prediction of body weight from linear body measurements in kashmir merino sheep. Advances in Animal and Veterinary Sciences 9: 189-193.

Rotımı E, Momoh O and Egahı J, 2020. Relationship between bodyweight and morphological traits in Sahelian goats of Nigeria using path analysis. Mustafa Kemal Üniversitesi Tarım Bilimleri Dergisi 25: 455-460. http://dx.doi.org/10. 37908/mkutbd.737231

Sabri GÜL, Keskin M, Güzey YZ, Behrem S and Gündüz Z, 2019. Path Analysis of the Relationship Between Weaning Weight and Some Morphological Traits in Awassi Lamb. Kahramanmaraş Sütçü İmam Üniversitesi Tarım ve Doğa Dergisi 22: 431-435. http://dx.doi.org/10.18016/ ksutarimdoga.vi. 558957

Shuaibu A, Ahmad NM, Ma'aruf BS, Maigado AI, Umar HA and Mijinyawa A, 2020. Estimation of live weight in Red Sokoto kids using linear body traits. Nigerian Journal of Animal Science 22: 40-47.

Temoso O, Coleman M, Baker D, Morley P, Baleseng L, Makgekgenene A and Bahta S, 2017. Using path analysis to predict bodyweight from body measurements of goats and sheep of communal rangelands in Botswana. South African Journal of Animal Science 47: 854-863. http://dx.doi.org/ 10.4314/sajas.v47i6.13

Tyasi TL, Mathye ND, Danguru LW, Rashijane LT, Mokoena K, Makgowo KM, Mathapo MC, Molabe KM, Bopape PM and Maluleke D, 2020. Correlation and path analysis of body weight and biometric traits of Nguni cattle breed. Journal of Advanced Veterinary and Animal Research 7: 148. http://dx.doi.org/10.5455/javar.2020.g404

Tyasi TL, Qin N, Jing Y, Mu F, Zhu HY, Liu D, Yuan S and Xu R, 2017. Assessment of relationship between body weight and body measurement traits of indigenous Chinese Dagu chickens using path analysis. Indian Journal of Animal Research 51: 588-593. http://dx.doi.org/10.0.73.117/ijar. v0iOF.6990

Tyasi TL, Qin N, Niu X, Sun X, Chen X, Zhu H, Zhang F and Xu $R$, 2018. Prediction of carcass weight from body measurement traits of Chinese indigenous Dagu male chickens using path coefficient analysis. Indian Journal of Animal Sciences 88: 744-8.

Van Wyk JB and Cloete SWP, 2019. Breed effects and nonadditive genetic variation in indigenous and commercial sheep in an extensive environment (Doctoral dissertation, University of the Free State).

Wishart H, Morgan-Davies C, Stott A, Wilson R and Waterhouse T, 2017. Liveweight loss associated with handling and weighing of grazing sheep. Small Ruminant Research 153: 163-170. https://doi.org/10.1016/i

Yakubu A, Muhammed MM, Ari MM, Musa-Azara IS and Omeje JN, 2015. Correlation and path coefficient analysis of body weight and morphometric traits of two exotic genetic groups of ducks in Nigeria. Bangladesh Journal of Animal Science 44: 1-9. 